\title{
Chemokine Receptors in Allergic Lung Disease
}

\author{
Dennis M. Lindell and Nicholas W. Lukacs
}

\begin{abstract}
Summary
This chapter is an attempt to integrate recent studies concerning the role of chemokine receptors in the initiation, development, and maintenance of allergic lung diseases collectively referred to as asthma. The pathogenesis of asthma involves the coordinated trafficking of inflammatory cells to the lungs and draining lymph nodes, as well as the activation of these inflammatory cells. Chemokine receptors and their ligands play a prominent role in directing the inflammation associated with allergic lung disease. T lymphocyte-mediated immune responses can be broadly categorized as being type 1 or type 2 , based on the cell types present and the associated cytokines produced. Allergic lung disease is a predominately type 2-mediated disease. The chemokine receptors CCR4, CCR6, and CCR8 serve to promote the recruitment of type $2 \mathrm{~T}$ (T helper 2; Th2) cells, whereas CXCR3 antagonizes type 2 and promotes type $1 \mathrm{~T}$ (T helper 1; Th1) cells. The pathophysiologic manifestations of asthma, including excessive mucus production, eosinophilia, and airway hyperreactivity, are dependent upon the trafficking and activation of eosinophils, mast cells, and goblet cells. Roles for chemokine receptors, including CCR4, CCR2, and CXCR4, in the trafficking and activation of these cell types during allergic lung disease are discussed. Finally, the incidence of allergic lung disease is increasing, and the costs associated with it are substantial. Chemokine receptor expression and use by inflammatory cells during allergic lung disease makes chemokine receptors an attractive therapeutic target. Implications for drug development are discussed in the context of experimental results.
\end{abstract}

Key Words: Allergy; asthma; lung; pulmonary; T cell; mast cell; eosinophil; inflammation; dendritic cell; IgE; B cell.

From: The Receptors: The Chemokine Receptors

Edited by: J. K. Harrison and N. W. Lukacs ( $)$ Humana Press Inc., Totowa, NJ 


\subsection{Introduction}

Allergic lung disease encompasses the development, establishment, and maintenance of inflammation leading to asthma. Allergic asthma is variable but is characterized by the following: altered lung function, airway hyperreactivity (AHR), chronic inflammation, excessive mucus production, goblet cell hyperplasia, and increased IgE production. In chronic disease, significant remodeling of the airways occurs including smooth muscle hypertrophy and peribronchial fibrosis. These responses have been examined extensively in animal models.

Initial steps in the development of allergic lung disease involve the exposure of genetically susceptible individuals to allergen via inhalation. Initial exposure results in the priming and expansion of allergen-specific $\mathrm{T}$ cells, as well as expansion of B cells and allergen-specific antibody production. Repeated exposure in susceptible individuals results in the expansion and trafficking of $\mathrm{T}$ helper 2 (Th2) cells, mast cells, and eosinophils to the lungs (Fig. 1). Cytokine production, including IL-4, IL-5, and IL-13, promotes the production of allergen-specific IgE by B cells, airway hyperresponsiveness, mucus production, and inflammation. Binding of specific antigen by $\operatorname{IgE}$ bound to mast cells

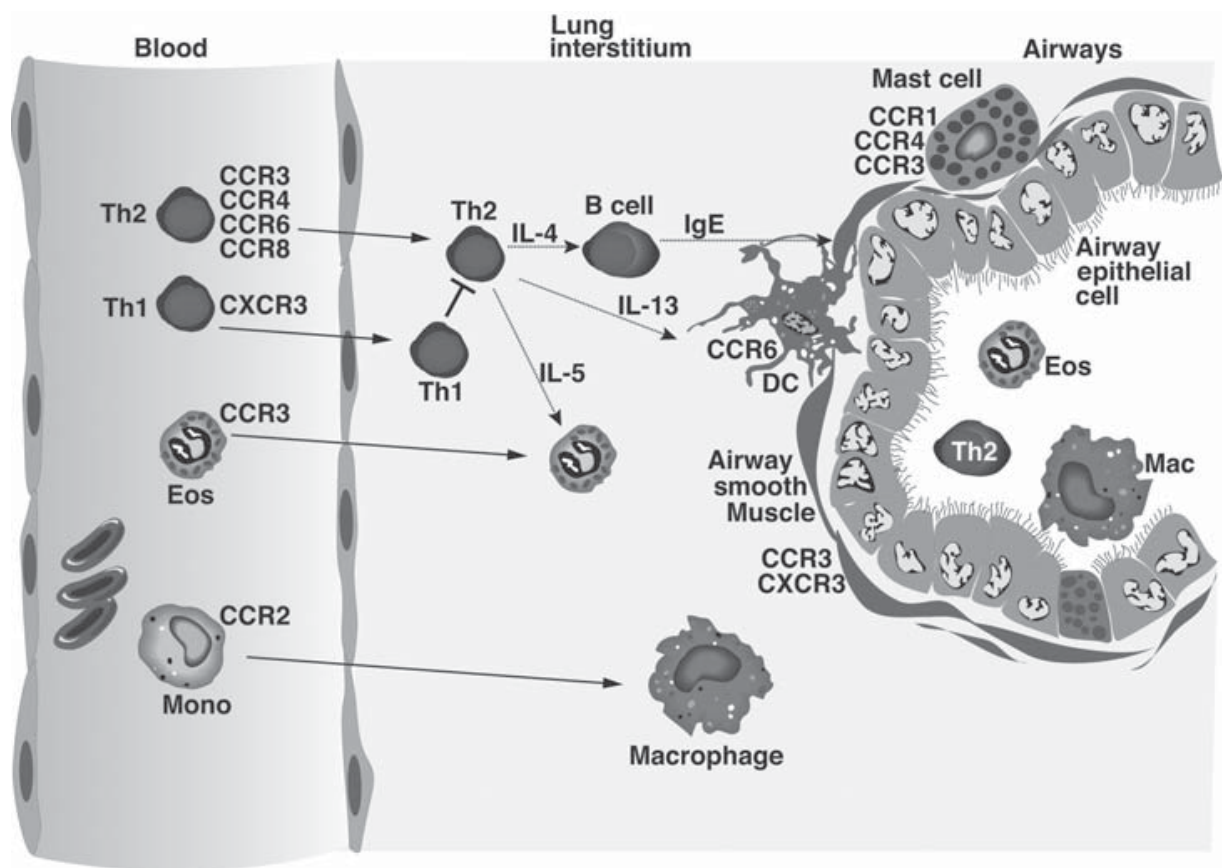

Fig.1. Expression of CC and CXC chemokine receptors by inflammatory and structural cells in allergic lung disease. Eos, eosinophil; Mac, macrophage; Mono, monocyte. 
triggers acute allergic events. Each of these events is dependent upon the coordinated production and expression of chemokine receptor/ligand systems. Chemokine receptors and ligands play essential roles in the trafficking, activation, and effector functions of inflammatory and structural cells (Table 1).

\subsection{Th1 versus Th2 Chemokine Receptor Profiles}

Although there are exceptions to the rule (1), differential chemokine receptor expression tends to be present under Th1 and Th2 inflammatory conditions. Under Th1 conditions, CXCR3 and, to a lesser extent, CCR5 predominate. Conversely, under Th2 conditions, CCR3, CCR4, and CCR8 are preferentially expressed. Thus, under Th1-promoting conditions, CXCR3 ligands including $10 \mathrm{kDa}$ interferon-gamma-induced protein (IP-10)/CXCL9, gamma interferoninduced monokine (MIG)/CXCL10, and interferon-inducible T-cell alpha chemoattractant (I-TAC)/CXCL11 preferentially attract Th1 T cells. CCR3, CCR4, and CCR8 ligands, including eotaxins/CCL 11, 24, 26, monocyte-derived chemokine (MDC)/CCL22, thymus associated regulatory chemokine (TARC)/ CCL17, and T-cell activation protein 3 (TCA-3)/CCL1, preferentially attract Th2 cells, eosinophils, mast cells, and basophils.

Clinical evidence tends to support the Th1/Th2 differential chemokine receptor paradigm, represented primarily as CXCR3 versus CCR4. Pulmonary $\mathrm{CCR} 4^{+} \mathrm{CD} 4^{+}$cells and levels of CCL17 and CCL22 were significantly increased in asthmatic children versus children with nonasthmatic chronic cough or without airway disease. In asthmatic children, $\mathrm{CCR} 4^{+} \mathrm{CD} 4^{+}$cells correlated positively with levels of CCL17, CCL22, serum IgE levels, and negatively with FEV 1 (forced expiratory volume in the first second of exhalation, a measure of lung function). Conversely, $\mathrm{CXCR} 3^{+} \mathrm{CD} 8^{+}$cells and levels of CXCL11 were significantly increased in children with nonatopic chronic cough compared with the other groups (2). These results have been recapitulated in segmental allergen challenge studies. In asthmatics, a majority of T cells in post-allergen challenge biopsies expressed CCR4 (3,4). Expression of the CCR4 ligands CCL22 and CCL17 was also upregulated on airway epithelial cells upon allergen challenge (3). CCR4 expression was not found on T cells from patients with chronic obstructive pulmonary disease, which instead expressed CXCR3 (4). Cumulatively, these results demonstrate an increase in CCR4-expressing $\mathrm{T}$ cells in allergic airways and increased production of CCL17 and CCL22. Furthermore, these results demonstrate that the increase in CCR4 expression by $\mathrm{T}$ cells in allergic lungs may serve to differentiate allergic from nonallergic inflammation.

One potential mechanism for the continued polarization of T-cell chemokine receptor expression during inflammatory lung disease is that chemokines can also serve as receptor antagonists. CXCR3 ligands act as antagonists of CCR3, and CCL11 can serve as an antagonist for CXCR3 $(5,6)$. Thus, Th1-type 


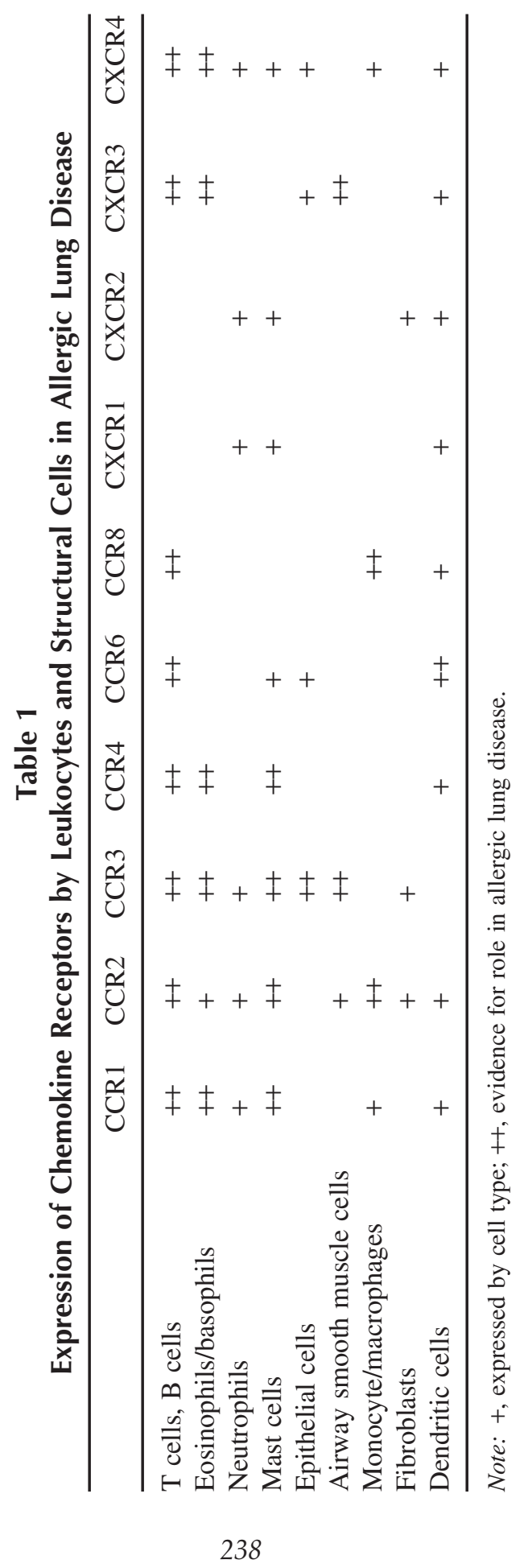


chemokines may simultaneously promote Th1 and antagonize Th2, similar to Th1 and Th2 cytokines.

\subsubsection{CCR4}

There is overwhelming evidence from humans that CCR4 and its principal ligands CCL17 and CCL22 are associated with allergic lung disease. The airway epithelium is thought to be the major producer of CCR4 ligands, although some studies have suggested that smooth muscle cells, mast cells, and even naïve $\mathrm{CD}^{+} \mathrm{T}$ cells may contribute (7). Increased expression of CCL17 and CCL22 mRNA has been demonstrated in asthmatic bronchial epithelium and submucosa (8). CCL17 and/or CCL22 were elevated in the serum and bronchoalveolar lavage (BAL) of asthmatics relative to controls $(9,10)$. Additionally, bronchial epithelial cells from asthmatic patients produced more CCL17 $(11,12)$. Thus, the production of CCR4 ligands is increased in asthmatic patients. In BAL of allergic asthmatic patients given serial antigen, CCL22 and CCL17 were highly increased compared with saline-challenged areas $(13,14)$. The increased levels of CCL17 and CCL22 correlated with lymphocyte numbers and the levels of IL-5 and IL-13 (14). Thus, within individual lungs, production of CCL17 and CCL22 correlate with areas of allergic inflammation.

Evidence from animal studies targeting the CCR4 axis in allergic lung disease has been less clear. Using a guinea-pig ovalbumin model, a CCR4 blocking monoclonal antibody did not significantly affect the development of allergic inflammation or the production of CCL11 and CCL22 (15). Only a modest decrease in $\mathrm{CCR}^{+}$Th cells was observed (15). On the other hand, neutralization of CCL22 attenuated interstitial eosinophilia in the mouse model of ovalbumin-induced allergic lung disease. This was accompanied by a decrease in AHR in CCL22-neutralized mice (16). Monoclonal antibody-mediated neutralization of CCL17 resulted in attenuated allergic disease in the ovalbumin model including decreases in AHR, eosinophilia, and Th2-type cytokines (17). In an adoptive transfer model using effector $\mathrm{CD} 4^{+} \mathrm{T}$ cells, both CCR 3 and CCR4 were involved in trafficking of Th2 cells to the lungs, with CCR3 mediating early recruitment of Th2 cells and CCR4 mediating the later phase (18). Cumulatively, these results demonstrate that CCL17 and CCL22, in part via the recruitment of $\mathrm{CCR} 4^{+} \mathrm{Th} 2$ cells, play a role in driving eosinophilia and airway hyperreactivity in the ovalbumin model of allergic lung disease. Similar to the results obtained in the ovalbumin models, in a live Aspergillus model of allergic lung disease, $\mathrm{CCR} 4^{-/-}$mice had attenuated airway hyperresponsiveness and attenuated eosinophilia at later time points after fungal challenge (19). Interestingly, $\mathrm{CCR}^{-/-}$mice had increased airway neutrophils and macrophages early day3 (d3) after fungal challenge, which was accompanied by an increase in IL-4 and IL-5 (19). Follow-up studies have demonstrated that both CCL17 
and CCL22 impair the innate antifungal immune response, thereby promoting the maintenance of acquired Th2-mediated asthmatic disease $(20,21)$. These results may be explained in part by the expression of CCR4 by other cell types including dendritic cells, platelets, T regulatory cells, and mast cells (22-25). Thus, even though expression data in human disease suggest that CCR4 and its ligands may be good targets for therapy, data from murine models of disease indicate that a diverse number of mechanisms may be controlled by CCR4.

\subsubsection{CCR6}

Another chemokine receptor associated with Th2 cells is CCR6. CCR6 is expressed by a subset of dendritic cells, primarily by immature dendritic cells, memory T cells, and B lymphocytes (26-28). The only known chemokine ligand for CCR6, MIP-3 $\alpha /$ CCL20, is expressed constitutively in some secondary lymphoid tissues, including murine spleen and human tonsils $(29,30)$. The predominant cell source of CCR6 ligands in the lungs is thought to be epithelial cells (31). Primary human bronchoepithelial cells stimulated with type 2 cytokines (IL-4 and IL-13) or particulate matter produced macrophage inflammatory protein 3- $\alpha$ (MIP-3 $\alpha$ )/CCL20, and this may be one mechanism for dendritic cell trafficking to the lung (32). The role of CCR6/CCL20 has been investigated by our laboratory using a cockroach antigen-induced allergic airway disease. CCL20 is induced within hours of allergen challenge (33). CCR6 ${ }^{-1-}$ mice were equivalently immunized, as assessed by T-cell cytokine production, but had attenuated airway hyperreactivity, fewer eosinophils, lower IL-5, and lower IgE levels than wild-type mice (33). CCL20 was not directly chemotactic for eosinophils at doses comparable with those used for CCL11-mediated chemotaxis (33), thus the effect on eosinophils was likely related to the lower IL-5. Type 2 cytokine and eosinophilia were reconstituted in $\mathrm{CCR}^{-/-}$mice by adoptive transfer of $\mathrm{T}$ cells from sensitized wild-type mice, however airway hyperreactivity was unaffected. Thus, CCR6 plays a role in promoting allergic lung disease, in part due to its expression on $\mathrm{T}$ cells, but also likely in part due to $\mathrm{T}$ cell-independent effects (34). Although the effects in $\mathrm{CCR} 6^{-1}$ mice demonstrated striking reductions in allergen sensitized and challenged mice, additional research is needed to identify the exact mechanism of the altered phenotype, which may include recruitment of dendritic cell (DC) subsets to the lung.

\subsubsection{CCR8}

A primary chemokine receptor associated with Th2-type responses is CCR8, which is also upregulated on Th2 cells derived in vitro. CCR8 is expressed by thymocytes, monocytes, as well as Th2 cells, and serves as the receptor for I309/TCA-3/CCL1. In humans, expression of CCR8 was found on T cells in endobronchial biopsies of asthmatic patients taken 24 hours after allergen 
challenge (35). Additionally, increased expression of the CCR8 ligand CCL1 has been reported during allergic lung disease (35). One study found impaired Th2 responses in $\mathrm{CCR}^{-/-}$mice in ovalbumin (OVA)- and cockroach antigeninduced models of allergic lung disease, as well as Schistosoma mansoni soluble egg antigen (SEA)-induced Th2 granuloma model. In each of these models, decreases in both Th2-type cytokines and eosinophils were present (36). Also using the OVA-induced model of allergic lung disease, two groups reported that $\mathrm{CCR}^{-/-}$mice developed similar eosinophilia, lung inflammation, and $\mathrm{Th} 2$ cytokine levels compared with wild-type mice $(35,37)$. The reason for discordance in these findings is unclear, but recent studies point to a role for CCR8 on other cell types including $\mathrm{CD} 4^{+} \mathrm{CD} 25^{+} \mathrm{T}$ cells and dendritic cells $(38,39)$. Thus, the role of CCR8 in development of allergic responses may be due in part to regulation of Th1-type responses by the production of IL-10. Further analyses will likely examine the potential mechanism of $\mathrm{T}$ regulatory (Treg) cell development and CCR8 expression.

\subsubsection{CXCR3}

CXCR3 is expressed by a number of cell types but preferentially on Th1 and T-cell type 1 (Tc1) cells. CXCR3 ligands CXCL9-11 were all originally identified as IFN- $\gamma$-inducible chemokines, so it comes as no surprise that CXCR3 ligands predominate under Th1 conditions. CXCR3-expressing cells predominate under type 1 conditions such as pulmonary sarcoidosis and chronic obstructive pulmonary disease (COPD) (3). The Th1/Th2 dogma would predict that the CXCR3 axis may serve to antagonize Th2 development, but in established allergic lung disease, the expression of CXCR3 and its ligands would be minimal. For the most part, published data support this view. For example, neutralization of CXCL9 in the airways at time of allergen challenge increased AHR, eosinophilia, and IL-4. Conversely, exogenous addition of CXCL9 reduced AHR and eosinophilia and increased IL-12 (40). Similarly, neutralization of CXCL10 resulted in exaggerated AHR and eosinophilia associated with decreased numbers of $\mathrm{CXCR}^{+} \mathrm{CD}^{+} \mathrm{T}$ cells (41). Interestingly, exogenous administration of CXCL10 to the airways attenuated early AHR but increased eosinophilia and later AHR (41). Thus, modulation of CXCR3 ligands has both expected and unexpected effects on allergic lung disease. This is likely due to the ability to recruit both Th1-type cells and eosinophils to the airways during allergen challenge.

CXCR3 is expressed highly in the lungs. At least two studies have found high expression levels of CXCR 3 on lung T cells in both normal and asthmatic patients compared with $\mathrm{T}$ cells in other sites $(42,43)$. After segmental allergen challenge in asthmatic patients, the CXCR3 ligand CXCL10 was upregulated (along with CCR4 ligands) at the site of allergen challenge, relative to saline-challenged sites 
(13). In another segmental allergen challenge study, CXCR3 was upregulated on airway eosinophils compared with peripheral blood (44). Thus evidence from clinical studies suggests that CXCR3 expression may be increased in allergic airways but may be increased in nonallergic airways as well.

The expression of CXCR 3 is not limited to Th1/Tc1 type cells and eosinophils during lung disease. Airway epithelial cells express functional CXCR3, binding of which results in mitogen-activated protein kinase (MAPK) activation, DNA synthesis, and chemotaxis (45). Additionally, CXCR3 was the most highly expressed chemokine receptor on lung mast cells (46), and specifically mast cells in airway smooth muscle (47). Smooth muscle cell-driven chemotaxis of mast cells was predominately CXCR3-mediated, and CXCL10 production by smooth muscle was increased in asthmatics relative to controls (47). Together, these results suggest a role for CXCR3 and its ligands in promoting allergic airway disease independent of CXCR3 expression by $\mathrm{T}$ cells. It is noteworthy that genetic studies have identified a polymorphism in CXCR3, which is associated with the risk of asthma development (48). The polymorphism is a $\mathrm{G} \rightarrow \mathrm{A}$ substitution, but the functional consequences of this polymorphism are not yet clear (48). This finding brings up the possibility that targeting of particular chemokine receptors during allergic airway disease may depend upon the genotype of the patient as well as the cell type expressing the receptor.

\subsection{CCR3}

Eosinophils are a hallmark of allergic airway disease. Eosinophils are recruited to airways and surrounding interstitial space during allergic disease. Mechanisms of action of chemokines on eosinophils include chemotaxis, as well as direct activation and prosurvival signals. Eosinophils are thought to be significant producers of eicosanoids, including prostaglandins and leukotrienes, as well as proteolytic enzymes that result in damage and remodeling of airways (49). The chemokine receptor that is predominately expressed on eosinophils is CCR3, which appears to mediate the most potent activating and recruitment responses. However, CCR3 is not only expressed by eosinophils but also by basophils, mast cells, and Th2 cells. Ligands for CCR3 include CCL 11, 24, 26 (eotaxin-1, -2,-3), as well as CCL 5, 7, 8, and 13. CCL11 induces chemotaxis and degranulation of eosinophils through the activation of extracellular signalregulated kinase 2 (ERK2) and p38 mitogen-activated protein kinases $(50,51)$. Interestingly, CXCR3 ligands CXCL 9-11 can behave as natural antagonists for CCR3 (5), providing evidence for competitive binding between chemokines that may regulate migration. The role of CCR3/CCL11 in the chemotaxis and activation of eosinophils during allergic lung disease has figured prominently in the literature and has been the focus of many drug discovery programs. 
Clinically, the expression of CCL11 and CCR3 are elevated in atopic asthmatics. CCL11 mRNA is produced by epithelial and endothelial cells, with CCR3 being predominately localized to eosinophils (52). Eotaxin levels were elevated in patients with acute asthma (53). Additionally, CCR $3^{+}$eosinophils were elevated in the bone marrow and peripheral blood of individuals with allergic asthma but not in atopic individuals in general $(54,55)$. Increased CCR3 expression was found on $\mathrm{CD}^{+}$and double-negative $\mathrm{T}$ cells in peripheral blood of dust mite allergic individuals (56). More recently, increased expression of CCR3 ligands CCL24 and CCL26 was found to be associated with persistent eosinophilic inflammation in the lungs of asthmatics (57). Thus, it is likely that multiple CCR3 ligands play a contributory role to the recruitment of eosinophils in the lungs and airways.

Animal models of allergic lung disease have demonstrated that CCR3 plays a prominent role in the recruitment of eosinophils to the lungs. However, the earliest studies examining CCL1 $11^{-/-}$mice indicated that there was little role for this ligand in allergic responses. In contrast, studies using $\mathrm{CCR} 3^{-/-}$mice have demonstrated that CCR3 plays a critical role in the recruitment of eosinophils to the lungs during allergen challenge (58). Surprisingly, more intraepithelial mast cells were present in CCR $3^{-1-}$ mice after allergen challenge, and CCR $3^{-1-}$ mice had exacerbated airway hyperreactivity (58). Studies using a combination of eotaxin- $1^{-/}$mice, eotaxin- $2^{-/-}$, eotaxin-1,2 double knockouts, and CCR3 $3^{-/-}$ mice have demonstrated redundancy between eotaxin- 1 and -2 for recruitment of eosinophils to the lungs (59). Although recent studies using anti-IL-5 to deplete eosinophils in human asthmatics have failed to attenuate disease (6062 ), the short-term nature of the studies have allowed justification for the continuation of CCR3 antagonist programs.

CCR3 blockade has received considerable attention as a target for therapeutics (63). A number of CCR3 antagonists including humanized antibodies and small-molecule inhibitors have been or are currently under development (6468). To date, 34 U.S. patents have been issued pertaining to CCR3 [U.S. PTO using ABST/(CCR3)]. Future clinical data will soon highlight the efficacy of this treatment strategy.

The expression of CCR3 is not limited to basophils, eosinophils, and Th2 cells. More recently, functional CCR3 has been described on airway epithelial cells (69), as well as on primary bronchial epithelial cells from patients with inflammatory lung diseases including asthma (69). Additionally, mast cells express CCR3 intracellularly, which can be mobilized to the surface upon activation via FceR. The combination of FceR plus eotaxin (and possibly other CCR3 ligands) led to enhanced IL-13 production (70), thereby providing an additional source of proallergic and profibrotic mediators. Another recent study demonstrated the expression of CCR3 on asthmatic airway smooth muscle (71); 
CCR3 was functional on these cells as evidenced by calcium flux, and eotaxin was chemotactic for airway smooth muscle (ASM) cells in vitro (71). Therefore, although CCR3 blockade may be useful for antagonizing the accumulation of eosinophils in the lungs during allergic lung disease, CCR3 antagonists are likely to have numerous effects on other cell types as well. These may offer additional beneficial effects for the treatment of asthma not provided by the previous studies using anti-IL-5, which targeted only eosinophils.

\subsection{CCR1}

CCR1 ligands play a role in the chemotaxis of eosinophils and other leukocytes during allergic lung disease $(72,73)$. CCR1 is expressed on several cell types including mast cells, neutrophils, monocytes, lymphocytes, and eosinophils and binds CCL3, CCL5, and CCL7, as well as a number of other chemokines. In a model of chronic fungal allergic lung disease, $\mathrm{CCR} 1^{-/-}$mice exhibited an enhanced type 1 response relative to wild-type mice and were protected from airway remodeling but had similar airway hyperresponsiveness (74). In the same model, a CCR1 antagonist attenuated airway inflammation, hyperresponsiveness, and remodeling (75). Recent data from our laboratory have pointed to a critical role for $\mathrm{CD}^{+} \mathrm{T}$ cells expressing CCR1 in a model of virus-induced exacerbation of allergic lung disease (76-79). Thus, CCR1 appears to be most relevant during pathogen-associated disease that promotes exacerbated airway responses. Additionally, there is evidence that CCR1 expression by eosinophils and mast cells may play a role in allergic lung disease. Mast cells migrate to CCL5 in vitro (80), and CCR $1^{+}$mast cells were found in the lungs of asthmatic patients, with comparatively few found in normal controls (25). Met-RANTES, a modified chemokine protein, inhibited eosinophil effector function, which was mediated at least in part via its effects on CCR1 blockade (81,82). A number of other antibody-based and small-molecule antagonists have been developed for CCR1 as well $(64,68,83)$. Although CCR1 antagonists have not performed well in clinical trials of autoimmune diseases, they have yet to be applied to asthmatic disease. Because many asthmatic exacerbations are caused by infectious agents, CCR1 antagonists may provide significant therapeutic effects.

\subsection{CCR2}

One of the earliest identified receptors associated with disease progression was CCR2. CCR2 is expressed by many cell types, including monocytes, dendritic cells, activated $\mathrm{T}$ cells, natural killer (NK) cells, and basophils. CCR2 ligands include CCL2, CCL7, CCL12, and CCL13. In particular, CCR2 
appears to play a critical role in a number of lung inflammatory diseases including asthma, acute respiratory distress syndrome (ARDS), COPD, and pulmonary fibrosis (84-88). However, the roles of CCR2 and CCR2 ligands in allergic lung disease have been controversial when applied to multiple animal models.

In a model of allergic fungal lung disease, $\mathrm{CCR} 2^{-/-}$mice exhibited decreased neutrophil recruitment, but exaggerated eosinophilia, and an enhanced type 2 response (89). Likewise, neutralization of a primary CCR2 ligand, CCL2, in the first 14 days after fungal conidia challenge also impaired fungal clearance and increased AHR. Conversely, overexpression of MCP-1 exaggerated fungal clearance and decreased AHR (90). However, neutralization of MCP-1 beginning at day 14 after conidia challenge resulted in attenuated AHR (90). Together, these results demonstrate that CCR2 and CCL2/MCP-1 play a role in the protective response to remove fungus but also a pathogenic role in perpetuating inflammation. Thus, examination of appropriate models of disease as well as phases of disease may dictate different mechanistic roles of a specific receptor.

Examination of models of allergen-induced disease have demonstrated divergent results in CCR2/CCL2-related mechanisms. Using a fungal allergeninduced model of allergic lung disease, mice deficient in either MCP-1 or CCR2 developed eosinophilic airway inflammation, goblet cell hyperplasia, airway hyperreactivity, elevations in serum $\mathrm{IgE}$, and airway fibrosis similar to those seen in wild-type mice (91). In the ovalbumin model of allergic lung disease, one group reported exaggerated allergic responses in $\mathrm{CCR} 2^{-/-}$mice (92), whereas another reported that $\mathrm{CCR} 2^{-/-}$mice had indistinguishable responses from wild-type mice (93). In models of allergen-induced disease, animals treated with anti-CCL2 had significantly reduced airway parameters related to mast cell activation and lymphocyte recruitment. Interestingly, CCL2 appears to be able to direct the immune response toward a Th2 phenotype through downregulation of IL-12 and direct skewing of T cells for increased IL-4 production (94). Thus, the role of CCR2 in allergic lung disease remains controversial and may depend upon a number of factors, including the experimental model (OVA; live Aspergillus; Aspergillus antigen) used to induce airway disease, as well as susceptibility of background strains of mice. CCR2 likely plays a role in modulating the innate immune response to viable organisms, as well as recruitment of mononuclear cells to the lungs. In the case of static antigens, such as Aspergillus antigen or ovalbumin, CCR2 seems to play a less prominent role. Comparatively few studies in humans have been published that either confirm or deny a role for CCR2 or its ligands in allergic lung disease, but those that do exist have not implicated CCR2 prominently (4). 


\subsection{CXCR4}

Classically regarded as primarily homeostatic based on its ubiquitous expression pattern and its role in stem cell trafficking, the CXCR4/CXCL12 stromalderived factor 1 (SDF-1) receptor/ligand pair also has a demonstrated role in allergic lung disease. One study reported that CXCR4 is increased on BAL eosinophils from patients with eosinophilic lung disease relative to eosinophils in peripheral blood (95). However, another study suggested increases in CCR4, CCR9, and CXCR3, without increased CXCR4 on BAL eosinophils (44). In animal models, antibody-mediated neutralization of CXCR4 or CXCL12 resulted in attenuated eosinophilia and reduced airway hyperresponsiveness in the OVA-induced allergic disease model (96). Conversely, overexpression of CXCL12 exacerbated inflammation. More recently, a number of studies have demonstrated, using a specific CXCR4 antagonist (97), attenuated allergic responses in allergic lung disease, as well as other inflammatory disease models (98-100). In the cockroach antigen model of allergic lung disease, this was accompanied by decreases in eosinophilia and $\mathrm{T}$ cells in the lungs and a shift in balance of lung cytokines from type 2 to type 1 (98). Therefore, in addition to its role in hematopoietic homeostasis, CXCR4 can play an important role in regulating allergic lung disease. It is likely that as CXCR4 can be found on multiple leukocyte populations, both innate and acquired immune cells, the targeting of this receptor may have an overall anti-inflammatory effect.

\subsection{CXCR1/CXCR2}

CXCR1 and CXCR2 are the predominant receptors used by neutrophils for chemotaxis. The potential role of IL-8/CXCL8 in human lung inflammation has received significant attention, with small-molecule antagonists developed recently (101). Neutrophilic inflammation and increased CXCL8 production were found in a number of chronic lung diseases including ARDS, COPD, as well as some allergic asthma (102). Additionally, genetic polymorphisms in CXCR1 have been identified that were present at increased frequency in children with asthma (103). Although CXCR1 and CXCR2 ligands are thought to be produced primarily by epithelial cells, eosinophils can make CXCL5/epithelial-derived neutrophil-activating protein 78 (ENA-78) and CXCL1/growthregulated protein alpha precursor (GRO- $\alpha$ ), implicating a potential role for these chemokine systems in chronic allergic disease $(104,105)$. These findings suggest that eosinophils can perpetuate inflammation, contributing to the inflamed state of the lungs.

In the live Aspergillus model of allergic lung disease, CXCR2 ${ }^{-/}$mice had fewer eosinophils and $\mathrm{T}$ cells (but interestingly similar neutrophil numbers). These were accompanied by decreased lung levels of IL-4, IL-5, and CCL11 
and an increase in CXCL9, CXCL10, and IFN- $\gamma$, suggesting a shift from type 2 to type 1 response (106). In the mouse model of respiratory syncytial virus (RSV) infection, CXCR2 neutralization resulted in attenuated airway hyperreactivity and ablation of mucus production in response to viral infection in the lungs (107). Viral clearance and neutrophil influx were similar between the two groups (107), demonstrating that CXCR2 promotes the development of lung disease in response to viral or fungal infection, but this role does not appear to occur via neutrophil recruitment. Neutralization of CXCL1 and CXCL8 in a cockroach antigen model of allergic lung disease resulted in attenuated neutrophils and lymphocytes in the airways and a decrease in serum $\operatorname{IgE}$ (108). Thus, CXCR2 may contribute to allergic lung disease via promoting both neutrophil dependent and/or neutrophil-independent mechanisms. Whether blocking CXCR2 has an effect on long-term disease or on specific aspects, such as mucus overproduction, may depend upon the nature of the exacerbating stimulus.

\subsection{CX3CR1/CX3CL1}

Fractalkine/CX3CL1 and its receptor CX3CR1 are the lone members of the CX3C family of chemokines. CX3CL1 can function both as an adhesion molecule in its membrane form and as a soluble chemokine, as it is attached to the cell membrane by an adhesion molecule-like stalk (109,110). CX3CR1/CX3CL1 has been studied extensively in atherosclerosis and kidney disease, but it may play a role in allergic disease as well. Serum CX3CL1 and expression of CX3CR1 by $\mathrm{T}$ cells were increased in asthmatic patients (111). Additionally, soluble CX3CL1 was upregulated in BAL after allergen challenge, as was membrane-bound CX3CL1 on endothelial and epithelial cells (111). Thus, CX3CL1 may provide a significant bound molecule allowing a "solid phase" chemokine gradient to be readily established. It has also been reported that fractalkine is produced by airway smooth muscle cells and may contribute to mast cell recruitment in asthma (112). Thus, there is some evidence that fractalkine/CX3CL1 and its receptor CX3CR1 is present during allergic asthmatic disease and may contribute to the pathogenesis of allergic lung disease.

\subsection{Conclusions}

There are several new frontiers that confront chemokine biologists. It is clear from the recent literature that chemokines have more functions than just chemotaxis. One area of challenge that has taken the lead is whether specific chemokine receptor systems have tissue-specific function. One ligand/receptor system that may prove to have lung-specific function is CCL18 and its receptor (which has yet to be identified). CCL18 was preferentially expressed in the lungs, associated with allergic disease, and was chemoattractant for Th2 cells and basophils (113). 
Studies of CCL18, however, will be hampered by the fact that human CCL18 has no mouse orthologue. A recent study that sought to determine chemotaxis of $\mathrm{T}$ cells generated under Th1 versus Th2 disease conditions in vivo found that the chemotactic responses of $\mathrm{T}$ cells were influenced strongly by the compartment from which they were obtained (lung vs. spleen). As would be predicted, T cells from the lungs of mice infected with Nippostrongylus brasiliensis (a Th2mediated response) migrated better to the CCR4 ligand CCL17 than T cells from the lungs of influenza-infected mice (114). However, T cells from the spleens of $N$. brasiliensis-infected mice migrated better to CCL17 than lung T cells (114). These findings are an example of the dynamic nature of chemotaxis, in that a combination of receptors and ligands are likely responsible for trafficking to, and even within, tissues. It is unlikely that any particular tissue compartment uses a single receptor system; rather, it may depend upon the nature of the immune/ inflammatory response generated in that tissue.

Another area that will certainly receive more attention in the future is the characterization of the proximal signals that mediate chemokine and chemokine-receptor expression. Recent studies have demonstrated that the production of CCL 11, 17, and 22 are signal transducer and activator of transcription (STAT) 6 dependent, whereas CXCL9 and CXCL10 production are dependent upon STAT1 and IFN- $\gamma(115)$. Although pattern recognition receptors (including Toll-like receptors, mannose receptor, etc.) have received considerable attention in host defense, their roles in allergic lung disease will likely be addressed more in the near future. Viral infection presents a likely situation for cross talk between innate immunity and allergic lung disease. Individuals with severe acute viral infection can present with signs and symptoms similar to allergic lung disease including inflammation, mucus production, and airway hyperresponsiveness. Studies from our laboratory and others have shown that viral infections can play a role in the exacerbation of allergic lung disease (76-78). Respiratory viral infections, including adenovirus, rhinovirus, and respiratory syncytial virus, contribute to the exacerbation of existing disease. CCR1, together with its ligands, was one chemokine receptor system that has been implicated in this phenomenon.

Another area that has gained increased attention is the role of matrix metalloproteinases (MMPs) and other modifiers of chemokine activity in allergic lung disease. MMPs have been shown to play a role in allergic lung disease that was related to chemokines $(116,117)$. The focus, however, has been primarily on the role of MMPs in airway remodeling. Coupled with the idea that MMPs can modify chemokines, such as converting inactive to active forms, or vice versa, suggests that MMPs are likely to play a significant role in the direct regulation of chemokines during allergic lung disease, especially given the role for Th2 cytokines in driving MMP production (118-120). 
In conclusion, the role of chemokines and their receptors continue to be investigated in asthmatic diseases. The role of specific chemokine receptor/ ligand systems will depend upon the nature of the inciting stimulus (i.e., noninfectious vs. infectious), as well as the intracellular (viral) versus extracellular (fungal) nature of microbes. Given the broad nature of the classification of asthmatic disease, a number of chemokine receptors as potential targets continue to be relevant.

\section{Acknowledgments}

The authors would like to acknowledge and thank Robin Kunkel for preparation of Fig. 1.

\section{References}

1. Morgan AJ, Symon FA, Berry MA, Pavord ID, Corrigan CJ, Wardlaw AJ. IL-4expressing bronchoalveolar $\mathrm{T}$ cells from asthmatic and healthy subjects preferentially express CCR 3 and CCR 4. J Allergy Clin Immunol 2005;116(3): 594-600.

2. Hartl D, Griese M, Nicolai T, et al. Pulmonary chemokines and their receptors differentiate children with asthma and chronic cough. J Allergy Clin Immunol 2005;115(4):728-736.

3. Panina-Bordignon P, Papi A, Mariani M, et al. The C-C chemokine receptors CCR4 and CCR8 identify airway $\mathrm{T}$ cells of allergen-challenged atopic asthmatics. J Clin Invest 2001;107(11):1357-1364.

4. Kallinich T, Schmidt S, Hamelmann E, et al. Chemokine-receptor expression on $\mathrm{T}$ cells in lung compartments of challenged asthmatic patients. Clin Exp Allergy 2005;35(1):26-33.

5. Loetscher P, Pellegrino A, Gong JH, et al. The ligands of CXC chemokine receptor 3, I-TAC, Mig, and IP10, are natural antagonists for CCR3. J Biol Chem 2001;276(5):2986-2991.

6. Weng Y, Siciliano SJ, Waldburger KE, et al. Binding and functional properties of recombinant and endogenous CXCR3 chemokine receptors. J Biol Chem 1998;273(29):18288-18291.

7. Hirata $\mathrm{H}$, Arima M, Cheng G, et al. Production of TARC and MDC by naive T cells in asthmatic patients. J Clin Immunol 2003;23(1):34-45.

8. Ying S, O'Connor B, Ratoff J, et al. Thymic stromal lymphopoietin expression is increased in asthmatic airways and correlates with expression of Th2-attracting chemokines and disease severity. J Immunol 2005;174(12):8183-8190.

9. Sekiya T, Yamada H, Yamaguchi M, et al. Increased levels of a TH2-type CC chemokine thymus and activation-regulated chemokine (TARC) in serum and induced sputum of asthmatics. Allergy 2002;57(2):173-177. 
10. Lezcano-Meza D, Negrete-Garcia MC, Dante-Escobedo M, Teran LM. The monocyte-derived chemokine is released in the bronchoalveolar lavage fluid of steady-state asthmatics. Allergy 2003;58(11):1125-1130.

11. Sekiya T, Miyamasu M, Imanishi M, et al. Inducible expression of a Th2-type $\mathrm{CC}$ chemokine thymus- and activation-regulated chemokine by human bronchial epithelial cells. J Immunol 2000;165(4):2205-2213.

12. Berin MC, Eckmann L, Broide DH, Kagnoff MF. Regulated production of the T helper 2-type T-cell chemoattractant TARC by human bronchial epithelial cells in vitro and in human lung xenografts. Am J Respir Cell Mol Biol 2001;24(4): 382-389.

13. Bochner BS, Hudson SA, Xiao HQ, Liu MC. Release of both CCR4-active and CXCR3-active chemokines during human allergic pulmonary late-phase reactions. J Allergy Clin Immunol 2003;112(5):930-934.

14. Pilette C, Francis JN, Till SJ, Durham SR. CCR4 ligands are up-regulated in the airways of atopic asthmatics after segmental allergen challenge. Eur Respir $\mathrm{J}$ 2004;23(6):876-884.

15. Conroy DM, Jopling LA, Lloyd CM, et al. CCR4 blockade does not inhibit allergic airways inflammation. J Leukoc Biol 2003;74(4):558-563.

16. Gonzalo JA, Pan Y, Lloyd CM, et al. Mouse monocyte-derived chemokine is involved in airway hyperreactivity and lung inflammation. J Immunol 1999;163(1): 403-411.

17. Kawasaki S, Takizawa $\mathrm{H}$, Yoneyama $\mathrm{H}$, et al. Intervention of thymus and activation-regulated chemokine attenuates the development of allergic airway inflammation and hyperresponsiveness in mice. J Immunol 2001;166(3):20552062.

18. Lloyd CM, Delaney T, Nguyen T, et al. CC chemokine receptor (CCR)3/eotaxin is followed by CCR4/monocyte-derived chemokine in mediating pulmonary $\mathrm{T}$ helper lymphocyte type 2 recruitment after serial antigen challenge in vivo. J Exp Med 2000;191(2):265-274.

19. Schuh JM, Power CA, Proudfoot AE, Kunkel SL, Lukacs NW, Hogaboam CM. Airway hyperresponsiveness, but not airway remodeling, is attenuated during chronic pulmonary allergic responses to Aspergillus in $\mathrm{CCR}^{-1-}$ mice. FASEB J 2002;16(10):1313-1315.

20. Hogaboam CM, Carpenter KJ, Schuh JM, Buckland KF. Aspergillus and asthmaany link? Med Mycol 2005;43(Suppl 1):S197-202.

21. Carpenter KJ, Hogaboam CM. Immunosuppressive effects of CCL17 on pulmonary antifungal responses during pulmonary invasive aspergillosis. Infect Immun 2005;73(11):7198-7207.

22. Abi-Younes S, Si-Tahar M, Luster AD. The CC chemokines MDC and TARC induce platelet activation via CCR4. Thromb Res 2001;101(4):279-289.

23. Iellem A, Mariani M, Lang R, et al. Unique chemotactic response profile and specific expression of chemokine receptors CCR4 and CCR8 by CD4(+)CD25(+) regulatory T cells. J Exp Med 2001;194(6):847-853. 
24. Yang ZZ, Novak AJ, Stenson MJ, Witzig TE, Ansell SM. Intratumoral CD $4^{+} \mathrm{CD} 25^{+}$ regulatory T-cell-mediated suppression of infiltrating $\mathrm{CD}^{+} \mathrm{T}$-cells in B-cell non-Hodgkin lymphoma. Blood 2006;107(9):3639-3646.

25. Amin K, Janson C, Harvima I, Venge P, Nilsson G. CC chemokine receptors CCR1 and CCR4 are expressed on airway mast cells in allergic asthma. J Allergy Clin Immunol 2005;116(6):1383-1386.

26. Krzysiek R, Lefevre EA, Bernard J, et al. Regulation of CCR6 chemokine receptor expression and responsiveness to macrophage inflammatory protein-3alpha/ CCL20 in human B cells. Blood 2000;96(7):2338-2345.

27. Fitzhugh DJ, Naik S, Gonzalez E, Caughman SW, Hwang ST. CC chemokine receptor 6 (CCR6) is a marker for memory $T$ cells that arrest on activated human dermal microvascular endothelium under shear stress. J Invest Dermatol 2000;115(2):332.

28. Kleinewietfeld M, Puentes F, Borsellino G, Battistini L, Rotzschke O, Falk K. CCR6 expression defines regulatory effector/memory-like cells within the CD25 ${ }^{+}$CD4 ${ }^{+}$T-cell subset. Blood 2005;105(7):2877-2886.

29. Cook DN, Prosser DM, Forster R, et al. CCR6 mediates dendritic cell localization, lymphocyte homeostasis, and immune responses in mucosal tissue. Immunity 2000;12(5):495-503.

30. Dieu MC, Vanbervliet B, Vicari A, et al. Selective recruitment of immature and mature dendritic cells by distinct chemokines expressed in different anatomic sites. J Exp Med 1998;188(2):373-386.

31. Starner TD, Barker CK, Jia HP, Kang Y, McCray PB Jr. CCL20 is an inducible product of human airway epithelia with innate immune properties. Am J Respir Cell Mol Biol 2003;29(5):627-633.

32. Reibman J, Hsu Y, Chen LC, Bleck B, Gordon T. Airway epithelial cells release MIP-3alpha/CCL20 in response to cytokines and ambient particulate matter. Am J Respir Cell Mol Biol 2003;28(6):648-654.

33. Lukacs NW, Prosser DM, Wiekowski M, Lira SA, Cook DN. Requirement for the chemokine receptor CCR6 in allergic pulmonary inflammation. J Exp Med 2001;194(4):551-555.

34. Lundy SK, Lira SA, Smit JJ, Cook DN, Berlin AA, Lukacs NW. Attenuation of allergen-induced responses in $\mathrm{CCR}^{-/-}$mice is dependent upon altered pulmonary T lymphocyte activation. J Immunol 2005;174(4):2054-2060.

35. Chung CD, Kuo F, Kumer J, et al. CCR8 is not essential for the development of inflammation in a mouse model of allergic airway disease. J Immunol 2003;170(1):581-587.

36. Chensue SW, Lukacs NW, Yang TY, et al. Aberrant in vivo T helper type 2 cell response and impaired eosinophil recruitment in CC chemokine receptor 8 knockout mice. J Exp Med 2001;193(5):573-584.

37. Goya I, Villares R, Zaballos A, et al. Absence of CCR8 does not impair the response to ovalbumin-induced allergic airway disease. J Immunol 2003;170(4): 2138-2146. 
38. Freeman CM, Chiu BC, Stolberg VR, et al. CCR8 is expressed by antigen-elicited, IL-10-producing $\mathrm{CD}^{+} \mathrm{CD} 25^{+} \mathrm{T}$ cells, which regulate $\mathrm{Th} 2$-mediated granuloma formation in mice. J Immunol 2005;174(4):1962-1970.

39. Gombert M, Dieu-Nosjean MC, Winterberg F, et al. CCL1-CCR8 interactions: an axis mediating the recruitment of $\mathrm{T}$ cells and Langerhans-type dendritic cells to sites of atopic skin inflammation. J Immunol 2005;174(8):5082-5091.

40. Thomas MS, Kunkel SL, Lukacs NW. Regulation of cockroach antigen-induced allergic airway hyperreactivity by the CXCR3 ligand CXCL9. J Immunol 2004;173(1):615-623.

41. Thomas MS, Kunkel SL, Lukacs NW. Differential role of IFN-gamma-inducible protein $10 \mathrm{kDa}$ in a cockroach antigen-induced model of allergic airway hyperreactivity: systemic versus local effects. J Immunol 2002;169(12):7045-7053.

42. Campbell JJ, Brightling CE, Symon FA, et al. Expression of chemokine receptors by lung $\mathrm{T}$ cells from normal and asthmatic subjects. J Immunol 2001;166(4): 2842-2848.

43. Kurashima K, Fujimura M, Myou S, et al. Effects of oral steroids on blood $\mathrm{CXCR}^{+}$and $\mathrm{CCR}^{+} \mathrm{T}$ cells in patients with bronchial asthma. Am J Respir Crit Care Med 2001;164(5):754-758.

44. Liu LY, Jarjour NN, Busse WW, Kelly EA. Chemokine receptor expression on human eosinophils from peripheral blood and bronchoalveolar lavage fluid after segmental antigen challenge. J Allergy Clin Immunol 2003;112(3):556-562.

45. Aksoy MO, Yang Y, Ji R, et al. CXCR3 Surface expression in human airway epithelial cells: cell cycle dependence and effect on cell proliferation. Am J Physiol Lung Cell Mol Physiol 2005;290(5):L909-918.

46. Brightling CE, Kaur D, Berger P, Morgan AJ, Wardlaw AJ, Bradding P. Differential expression of CCR3 and CXCR3 by human lung and bone marrow-derived mast cells: implications for tissue mast cell migration. J Leukoc Biol 2005; 77(5):759-766.

47. Brightling CE, Ammit AJ, Kaur D, et al. The CXCL10/CXCR3 axis mediates human lung mast cell migration to asthmatic airway smooth muscle. Am J Respir Crit Care Med 2005;171(10):1103-1108.

48. Cheong HS, Park CS, Kim LH, et al. CXCR3 polymorphisms associated with risk of asthma. Biochem Biophys Res Commun 2005;334(4):1219-1225.

49. Bandeira-Melo C, Bozza PT, Weller PF. The cellular biology of eosinophil eicosanoid formation and function. J Allergy Clin Immunol 2002;109(3):393400 .

50. Kampen GT, Stafford S, Adachi T, et al. Eotaxin induces degranulation and chemotaxis of eosinophils through the activation of ERK2 and p38 mitogen-activated protein kinases. Blood 2000;95(6):1911-1917.

51. Cui $\mathrm{CH}$, Adachi $\mathrm{T}$, Oyamada $\mathrm{H}$, et al. The role of mitogen-activated protein kinases in eotaxin-induced cytokine production from bronchial epithelial cells. Am J Respir Cell Mol Biol 2002;27(3):329-335.

52. Ying S, Robinson DS, Meng Q, et al. Enhanced expression of eotaxin and CCR3 mRNA and protein in atopic asthma. Association with airway hyperresponsive- 
ness and predominant co-localization of eotaxin mRNA to bronchial epithelial and endothelial cells. Eur J Immunol 1997;27(12):3507-3516.

53. Lilly CM, Woodruff PG, Camargo CA Jr, et al. Elevated plasma eotaxin levels in patients with acute asthma. J Allergy Clin Immunol 1999;104(4 Pt 1): 786-790.

54. Robinson DS, North J, Zeibecoglou K, et al. Eosinophil development and bone marrow and tissue eosinophils in atopic asthma. Int Arch Allergy Immunol 1999;118(2-4):98-100.

55. Zeibecoglou K, Ying S, Yamada T, et al. Increased mature and immature CCR3 messenger RNA+ eosinophils in bone marrow from patients with atopic asthma compared with atopic and nonatopic control subjects. J Allergy Clin Immunol 1999;103(1 Pt 1):99-106.

56. Wang CR, Chen PC, Liu MF. Increased circulating CCR $3^{+}$type 2 helper T cells in house dust mite-sensitive Chinese patients with allergic diseases. Asian Pac J Allergy Immunol 2003;21(4):205-210.

57. Ravensberg AJ, Ricciardolo FL, van Schadewijk A, et al. Eotaxin-2 and eotaxin-3 expression is associated with persistent eosinophilic bronchial inflammation in patients with asthma after allergen challenge. J Allergy Clin Immunol 2005;115(4):779-785.

58. Humbles AA, Lu B, Friend DS, et al. The murine CCR3 receptor regulates both the role of eosinophils and mast cells in allergen-induced airway inflammation and hyperresponsiveness. Proc Natl Acad Sci U S A 2002;99(3):14791484.

59. Pope SM, Zimmermann N, Stringer KF, Karow ML, Rothenberg ME. The eotaxin chemokines and CCR3 are fundamental regulators of allergen-induced pulmonary eosinophilia. J Immunol 2005;175(8):5341-5350.

60. Leckie MJ, ten Brinke A, Khan J, et al. Effects of an interleukin-5 blocking monoclonal antibody on eosinophils, airway hyper-responsiveness, and the late asthmatic response. Lancet 2000;356(9248):2144-2148.

61. Flood-Page PT, Menzies-Gow AN, Kay AB, Robinson DS. Eosinophil's role remains uncertain as anti-interleukin-5 only partially depletes numbers in asthmatic airway. Am J Respir Crit Care Med 2003;167(2):199-204.

62. Buttner C, Lun A, Splettstoesser T, Kunkel G, Renz H. Monoclonal antiinterleukin-5 treatment suppresses eosinophil but not T-cell functions. Eur Respir J 2003;21(5):799-803.

63. Bertrand CP, Ponath PD. CCR3 blockade as a new therapy for asthma. Expert Opin Invest Drugs 2000;9(1):43-52.

64. Sabroe I, Peck MJ, Van Keulen BJ, et al. A small molecule antagonist of chemokine receptors CCR1 and CCR3. Potent inhibition of eosinophil function and CCR3-mediated HIV-1 entry. J Biol Chem 2000;275(34):25985-25992.

65. White JR, Lee JM, Dede K, et al. Identification of potent, selective non-peptide $\mathrm{CC}$ chemokine receptor-3 antagonist that inhibits eotaxin-, eotaxin-2-, and monocyte chemotactic protein-4-induced eosinophil migration. J Biol Chem 2000; 275(47):36626-36631. 
66. Saeki T, Ohwaki K, Naya A, et al. Identification of a potent and nonpeptidyl ccr3 antagonist. Biochem Biophys Res Commun 2001;281(3):779-782.

67. Wacker DA, Santella JB 3rd, Gardner DS, et al. CCR3 antagonists: a potential new therapy for the treatment of asthma. Discovery and structure-activity relationships. Bioorg Med Chem Lett 2002;12(13):1785-1789.

68. Morokata T, Suzuki K, Masunaga Y, et al. A novel, selective, and orally available antagonist for CC chemokine receptor 3. J Pharmacol Exp Ther 2006;317(1):244-250.

69. Stellato C, Brummet ME, Plitt JR, et al. Expression of the C-C chemokine receptor CCR3 in human airway epithelial cells. J Immunol 2001;166(3):14571461.

70. Price KS, Friend DS, Mellor EA, De Jesus N, Watts GF, Boyce JA. CC chemokine receptor 3 mobilizes to the surface of human mast cells and potentiates immunoglobulin E-dependent generation of interleukin 13. Am J Respir Cell Mol Biol 2003;28(4):420-427.

71. Joubert P, Lajoie-Kadoch S, Labonte I, et al. CCR3 expression and function in asthmatic airway smooth muscle cells. J Immunol 2005;175(4):2702-2708.

72. Lukacs NW, Standiford TJ, Chensue SW, Kunkel RG, Strieter RM, Kunkel SL. C-C chemokine-induced eosinophil chemotaxis during allergic airway inflammation. J Leukoc Biol 1996;60(5):573-578.

73. Gonzalo JA, Lloyd CM, Wen D, et al. The coordinated action of CC chemokines in the lung orchestrates allergic inflammation and airway hyperresponsiveness. J Exp Med 1998;188(1):157-167.

74. Blease K, Mehrad B, Standiford TJ, et al. Airway remodeling is absent in $\mathrm{CCR}^{-1-}$ mice during chronic fungal allergic airway disease. J Immunol 2000; 165(3):1564-1572.

75. Carpenter KJ, Ewing JL, Schuh JM, et al. Therapeutic targeting of CCR1 attenuates established chronic fungal asthma in mice. Br J Pharmacol 2005;145(8):11601172 .

76. Schaller M, Hogaboam CM, Lukacs N, Kunkel SL. Respiratory viral infections drive chemokine expression and exacerbate the asthmatic response. J Allergy Clin Immunol 2006;118(2):295-302.

77. John AE, Gerard CJ, Schaller M, et al. Respiratory syncytial virus-induced exaggeration of allergic airway disease is dependent upon CCR1-associated immune responses. Eur J Immunol 2005;35(1):108-116.

78. John AE, Berlin AA, Lukacs NW. Respiratory syncytial virus-induced CCL5/ RANTES contributes to exacerbation of allergic airway inflammation. Eur J Immunol 2003;33(6):1677-1685.

79. Schaller MA, Lundy SK, Huffnagle GB, Lukacs NW. CD8+ T cell contributions to allergen induced pulmonary inflammation and airway hyperreactivity. Eur J Immunol 2005;35(7):2061-2070.

80. Mattoli S, Ackerman V, Vittori E, Marini M. Mast cell chemotactic activity of RANTES. Biochem Biophys Res Commun 1995;209(1):316-321. 
81. Elsner J, Petering H, Hochstetter R, et al. The CC chemokine antagonist MetRANTES inhibits eosinophil effector functions through the chemokine receptors CCR1 and CCR3. Eur J Immunol 1997;27(11):2892-2898.

82. Chvatchko Y, Proudfoot AE, Buser R, et al. Inhibition of airway inflammation by amino-terminally modified RANTES/CC chemokine ligand 5 analogues is not mediated through CCR3. J Immunol 2003;171(10):5498-5506.

83. Saeki T, Naya A. CCR1 chemokine receptor antagonist. Curr Pharm Des 2003;9(15):1201-1208.

84. Spagnolo P, Renzoni EA, Wells AU, et al. C-C chemokine receptor 2 and sarcoidosis: association with Lofgren's syndrome. Am J Respir Crit Care Med 2003;168(10):1162-1166.

85. Schuyler M, Gott K, Cherne A. Experimental hypersensitivity pneumonitis: role of MCP-1. J Lab Clin Med 2003;142(3):187-195.

86. Rose CE Jr, Sung SS, Fu SM. Significant involvement of CCL2 (MCP-1) in inflammatory disorders of the lung. Microcirculation 2003;10(3-4):273-288.

87. Hildebrandt GC, Duffner UA, Olkiewicz KM, et al. A critical role for CCR2/ MCP-1 interactions in the development of idiopathic pneumonia syndrome after allogeneic bone marrow transplantation. Blood 2004;103(6):2417-2426.

88. Moore BB, Paine R 3rd, Christensen PJ, et al. Protection from pulmonary fibrosis in the absence of CCR2 signaling. J Immunol 2001;167(8):4368-4377.

89. Blease K, Mehrad B, Standiford TJ, et al. Enhanced pulmonary allergic responses to Aspergillus in CCR2 ${ }^{-/}$mice. J Immunol 2000;165(5):2603-2611.

90. Blease K, Mehrad B, Lukacs NW, Kunkel SL, Standiford TJ, Hogaboam CM. Antifungal and airway remodeling roles for murine monocyte chemoattractant protein-1/CCL2 during pulmonary exposure to Asperigillus fumigatus conidia. J Immunol 2001;166(3):1832-1842.

91. Koth LL, Rodriguez MW, Bernstein XL, et al. Aspergillus antigen induces robust Th2 cytokine production, inflammation, airway hyperreactivity and fibrosis in the absence of MCP-1 or CCR2. Respir Res 2004;5(1):12.

92. Kim Y, Sung S, Kuziel WA, Feldman S, Fu SM, Rose CE Jr. Enhanced airway Th2 response after allergen challenge in mice deficient in CC chemokine receptor-2 (CCR2). J Immunol 2001;166(8):5183-5192.

93. MacLean JA, De Sanctis GT, Ackerman KG, et al. CC chemokine receptor-2 is not essential for the development of antigen-induced pulmonary eosinophilia and airway hyperresponsiveness. J Immunol 2000;165(11):6568-6575.

94. Campbell EM, Charo IF, Kunkel SL, et al. Monocyte chemoattractant protein-1 mediates cockroach allergen-induced bronchial hyperreactivity in normal but not $\mathrm{CCR}^{-1-}$ mice: the role of mast cells. J Immunol 1999;163(4):2160-2167.

95. Nagase H, Kudo K, Izumi S, et al. Chemokine receptor expression profile of eosinophils at inflamed tissue sites: decreased CCR3 and increased CXCR4 expression by lung eosinophils. J Allergy Clin Immunol 2001;108(4):563-569.

96. Gonzalo JA, Lloyd CM, Peled A, Delaney T, Coyle AJ, Gutierrez-Ramos JC. Critical involvement of the chemotactic axis CXCR4/stromal cell-derived factor-1 
alpha in the inflammatory component of allergic airway disease. J Immunol 2000;165(1):499-508.

97. Hatse S, Princen K, Bridger G, De Clercq E, Schols D. Chemokine receptor inhibition by AMD3100 is strictly confined to CXCR4. FEBS Lett 2002; 527(1-3):255-262.

98. Lukacs NW, Berlin A, Schols D, Skerlj RT, Bridger GJ. AMD3100, a CxCR4 antagonist, attenuates allergic lung inflammation and airway hyperreactivity. Am J Pathol 2002;160(4):1353-1360.

99. Matthys P, Hatse S, Vermeire K, et al. AMD3100, a potent and specific antagonist of the stromal cell-derived factor-1 chemokine receptor CXCR4, inhibits autoimmune joint inflammation in IFN-gamma receptor-deficient mice. J Immunol 2001;167(8):4686-4692.

100. Hogaboam CM, Carpenter KJ, Schuh JM, Proudfoot AA, Bridger G, Buckland $\mathrm{KF}$. The therapeutic potential in targeting CCR5 and CXCR4 receptors in infectious and allergic pulmonary disease. Pharmacol Ther 2005;107(3):314-328.

101. Widdowson KL, Elliott JD, Veber DF, et al. Evaluation of potent and selective small-molecule antagonists for the CXCR2 chemokine receptor. J Med Chem 2004;47(6):1319-1321.

102. Pease JE, Sabroe I. The role of interleukin-8 and its receptors in inflammatory lung disease: implications for therapy. Am J Respir Med 2002;1(1):19-25.

103. Stemmler S, Arinir U, Klein W, et al. Association of interleukin-8 receptor alpha polymorphisms with chronic obstructive pulmonary disease and asthma. Genes Immun 2005;6(3):225-230.

104. Persson T, Monsef N, Andersson P, et al. Expression of the neutrophil-activating CXC chemokine ENA-78/CXCL5 by human eosinophils. Clin Exp Allergy 2003;33(4):531-537.

105. Persson-Dajotoy T, Andersson P, Bjartell A, Calafat J, Egesten A. Expression and production of the CXC chemokine growth-related oncogene-alpha by human eosinophils. J Immunol 2003;170(10):5309-5316.

106. Schuh JM, Blease K, Hogaboam CM. CXCR2 is necessary for the development and persistence of chronic fungal asthma in mice. J Immunol 2002;168(3): 1447-1456.

107. Miller AL, Strieter RM, Gruber AD, Ho SB, Lukacs NW. CXCR2 regulates respiratory syncytial virus-induced airway hyperreactivity and mucus overproduction. J Immunol 2003;170(6):3348-3356.

108. McKinley L, Kim J, Bolgos GL, Siddiqui J, Remick DG. CXC chemokines modulate IgE secretion and pulmonary inflammation in a model of allergic asthma. Cytokine 2005;32(3-4):178-185.

109. Umehara H, Goda S, Imai T, et al. Fractalkine, a CX3C-chemokine, functions predominantly as an adhesion molecule in monocytic cell line THP-1. Immunol Cell Biol 2001;79(3):298-302.

110. Haskell CA, Cleary MD, Charo IF. Molecular uncoupling of fractalkine-mediated cell adhesion and signal transduction. Rapid flow arrest of CX3CR1-expressing cells is independent of G-protein activation. J Biol Chem 1999;274(15):1005310058. 
111. Rimaniol AC, Till SJ, Garcia G, et al. The CX3C chemokine fractalkine in allergic asthma and rhinitis. J Allergy Clin Immunol 2003;112(6):1139-1146.

112. El-Shazly A, Berger P, Girodet PO, et al. Fraktalkine produced by airway smooth muscle cells contributes to mast cell recruitment in asthma. J Immunol 2006;176(3):1860-1868.

113. de Nadai P, Charbonnier AS, Chenivesse C, et al. Involvement of CCL18 in allergic asthma. J Immunol 2006;176(10):6286-6293.

114. Debes GF, Dahl ME, Mahiny AJ, et al. Chemotactic responses of IL-4-, IL-10-, and IFN-gamma-producing $\mathrm{CD} 4^{+} \mathrm{T}$ cells depend on tissue origin and microbial stimulus. J Immunol 2006;176(1):557-566.

115. Fulkerson PC, Zimmermann N, Hassman LM, Finkelman FD, Rothenberg ME. Pulmonary chemokine expression is coordinately regulated by STAT1, STAT6, and IFN-gamma. J Immunol 2004;173(12):7565-7574.

116. Corry DB, Kiss A, Song LZ, et al. Overlapping and independent contributions of MMP2 and MMP9 to lung allergic inflammatory cell egression through decreased CC chemokines. FASEB J 2004;18(9):995-997.

117. Corry DB, Rishi K, Kanellis J, et al. Decreased allergic lung inflammatory cell egression and increased susceptibility to asphyxiation in MMP2-deficiency. Nat Immunol 2002;3(4):347-353.

118. McQuibban GA, Gong JH, Tam EM, McCulloch CA, Clark-Lewis I, Overall CM. Inflammation dampened by gelatinase A cleavage of monocyte chemoattractant protein-3. Science 2000;289(5482):1202-1206.

119. McQuibban GA, Butler GS, Gong JH, et al. Matrix metalloproteinase activity inactivates the CXC chemokine stromal cell-derived factor-1. J Biol Chem 2001;276(47):43503-43508.

120. McQuibban GA, Gong JH, Wong JP, Wallace JL, Clark-Lewis I, Overall CM. Matrix metalloproteinase processing of monocyte chemoattractant proteins generates $\mathrm{CC}$ chemokine receptor antagonists with anti-inflammatory properties in vivo. Blood 2002;100(4):1160-1167. 